\title{
Feasibility of hydrogen compression in an electrochemical system: focus on water transport mechanisms
}

\author{
G. Sdanghi $^{1,2 *}$, J. Dillet ${ }^{2}$, S. Didierjean ${ }^{2}$, V. Fierro ${ }^{1}$, G. Maranzana $^{2}$
}

${ }^{1}$ Institut Jean Lamour, UMR 7198 CNRS and Université de Lorraine, Épinal, France

${ }^{2}$ Laboratoire d'Energétique et de Mécanique Théorique et Appliquée, UMR 7563 CNRS and Université de Lorraine, Vandœuvre-lès-Nancy, France

[*] Corresponding author: giuseppe.sdanghi@univ-lorraine.fr

\begin{abstract}
In this study, the behavior of an electrochemical hydrogen compressor (EHC) able to compress hydrogen up to 32 bar was investigated. The current density distribution along the EHC was measured using a segmented cell. It was found to decrease from $0.75 \mathrm{~A} \mathrm{~cm}^{-2}$ to $0.65 \mathrm{~A} \mathrm{~cm}^{-2}$ along the EHC when using Nafion 117 and when high relative humidity hydrogen was fed to the EHC (at $0.66 \mathrm{~A} \mathrm{~cm}^{-2}$ and $0.36 \mathrm{~V}$ ). This drop corresponds to a decrease of the relative humidity of the hydrogen flow from 90 to $55 \%$ along the gas channels at the anode side, evidencing the local dehydration of the PEM due to the unbalanced water transport across the membrane. As a consequence, the membrane resistance increases, thus a higher voltage must be supplied to the EHC in order to maintain good performances, decreasing the overall efficiency. On the other hand, unstable operating conditions were observed when using hydrogen with a low relative humidity.
\end{abstract}

A pseudo-2D model was developed along with experimental studies to estimate the physical parameters enhancing the efficiency of the EHC. A higher efficiency was obtained when using a thinner membrane than Nafion 117 (53\% vs. $37 \%$, at $60^{\circ} \mathrm{C}$ and $0.66 \mathrm{~A} \mathrm{~cm}^{-2}$ ).

Keywords: hydrogen electrochemical compression, polymer electrolyte, water management 


\section{Introduction}

Compression is nowadays the most recommended method to store hydrogen for automotive applications [1] as it allows an increase of the hydrogen volumetric energy density, e.g. from $0.01079 \mathrm{MJ} \mathrm{L}^{-1}$ at 1 bar and $15^{\circ} \mathrm{C}$ to $4.6 \mathrm{MJ} \mathrm{L}^{-1}$ at 700 bar and $15^{\circ} \mathrm{C}$. For applications demanding high flow rates and high discharge pressures, mechanical compressors, such as the piston compressors and diaphragm compressors [2,3], are employed. Even though these technologies are widely used worldwide, they exhibit several drawbacks, as: (i) many moving components during operation; (ii) noise and vibration; (iii) possibility of contaminating hydrogen because of the use of lubricating oils; (iv) operational and maintenance difficulties; and (v) large dimensions.

In this frame, the electrochemical hydrogen compressor (EHC) seems to be a valid alternative for compression up to 1000 bar [4], as it provides pure hydrogen in a silent and practical system, with a lower capital cost and energy requirements compared to a mechanical compressor [5]. In an EHC, hydrogen at atmospheric pressure is fed to the anode of an electrochemical cell where the oxidation reaction occurs, thus hydrogen splits into protons and electrons while electric energy is provided to the system. Protons cross a solid polymer electrolyte membrane (PEM) towards the cathode where protons reduction takes place producing high-pressure hydrogen. Grigoriev et al. [6] showed that it is possible to compress hydrogen from atmospheric pressure up to 48 bar in a single EHC by applying a cell voltage of $140 \mathrm{mV}$ and at $0.2 \mathrm{~A} \mathrm{~cm}^{-2}$, with a corresponding energy consumption of around $0.3 \mathrm{kWh} \mathrm{Nm}^{-3}$. Nevertheless, it is quite hard to achieve very high pressures in an EHC because of the occurring hydrogen permeation from the cathode to the anode side [7]. Rohland et al. [8] showed that the hydrogen permeation linearly increases with the pressure gradient. Moreover, they found that the higher the cell temperature the higher the hydrogen back diffusion: a diffusion rate of around $2 \mathrm{~mA} \mathrm{~cm}{ }^{-2}$ was 
obtained at $24^{\circ} \mathrm{C}$, whereas $6 \mathrm{~mA} \mathrm{~cm}^{-2}$ were obtained at $70^{\circ} \mathrm{C}$ and 15 bar. Grigoriev et al. [9] carried out a numerical investigation to estimate the maximum output pressure reachable by a single EHC. They found that high output pressures are achievable at low temperatures mainly because of the lower hydrogen permeation.

The EHC was found to be more economical and convenient than a mechanical compressor, as the capital expenditure for an EHC is around $\$ 170-1700 \mathrm{~kg}^{-1}$ day $^{-1}$ compared to $\$ 2300 \mathrm{~kg}^{-1} \mathrm{day}^{-}$ ${ }^{1}$ of a hydrogen reciprocating compressor [10]. Moton et al. [11] carried out a deep technoeconomic analysis of an EHC, finding that the cost of both the EHC and the balance of plant (BOP) increases in a non-linear way with the outlet pressure in order to withstand the higher mechanical loads and leaks. Furthermore, they found that the membrane-electrode-assembly (MEA) contributes the most to the cost increase, as it covers $45 \%$ of the total costs. Wu et al. [12] investigated the possibility of using non-fluorinated membranes with the aim of reducing costs, but this leads to a decrease in efficiency compared to Nafion-based membranes. For all these reasons, several authors found that an outlet pressure as high as 150 bar is recommended in order to reach satisfying efficiencies at acceptable costs $[5,8,11]$. Nevertheless, the abovementioned mechanical limitations can be overcome by connecting several cells in series: in this way, the pressure of 700 bar demanded for hydrogen automotive applications can be reached with a minimum of 4 stages of single cell compressors [14]. Such a solution allows reaching even higher pressures and efficiencies of $90 \%$ for small hydrogen flowrates $[15,16]$.

Water management is one of the key factors affecting the performance of an EHC. Alike in the PEM fuel cells (PEMFCs), the membrane has to be hydrated in order to enhance its proton conductivity [17]. However, water is not a reaction product in an EHC, thus it needs to be fed along with hydrogen in order to preserve the optimal hydration degree of the membrane. Casati et al. [18] showed that better control of the membrane hydration degree can be reached by adopting tensiostatic operating conditions instead of galvanostatic ones. Onda et al. [19] found 
that both the relative humidity of the hydrogen flow and the current density distribution decrease along the channel direction during operation. This behavior was found to be directly related to the water transport across the membrane. In fact, the unbalanced contribution of the two main water transport mechanisms across the membrane, i.e. the electro-osmotic drag and the water back diffusion, can lead to the local dehydration of the membrane, which entails the increase of the local electric resistance. The main consequence of these operating heterogeneities could be a dramatic increase in the voltage to supply, which would reduce the overall efficiency of the system.

In this study, the local behavior of an EHC was investigated through both an experimental and a numerical approach. A segmented cell was used to perform a distributed performance analysis of the EHC. This diagnostic tool allows measuring the current density at specific segments of the MEA, which are electrically independent of the others [20]. In this way, the distribution of both the current densities and the electric resistances along the gas channel direction can be obtained, evidencing the local heterogeneities arising during operation. The segmented cell technology has been already used for investigating the PEM fuel cell durability [21-23] as well as that of PEM electrolysis cells [24], but it was never used for an EHC, as far as we know. The effect of the current density supplied to the system, the humidity of the feed gas and the membrane thickness on the local current density distribution was evaluated and discussed.

A pseudo-2D model was developed and validated by comparison to the obtained experimental data. This model takes into account both the overall mass and energy balances occurring in the EHC and the heterogeneities in the relative humidity along the gas distribution channels. The model also allowed investigating the effect of the aforementioned operating parameters on the EHC performance, in order to optimize the system and enhance its overall efficiency. 


\section{Experimental}

A single $30 \times 1 \mathrm{~cm}^{2}$ cell segmented into 20 electrically-insulated parts of $1.5 \mathrm{~cm}^{2}$ each was used, a detailed description is given elsewhere [25,26]. All segments were connected after the measurement system so that they operated at identical voltage. The local current densities were measured using shunt resistors $(5 \mathrm{~m} \Omega)$, with an uncertainty of $\pm 1 \mathrm{~mA}$. The schema of the EHC along with the BOP is shown in Figure 1. An external power supply of nominal capacity 1500 W was used. The EHC temperature was set by using a hot water circulating system mechanized in the support plates and driven by a platinum Pt100 probe. Hydrogen was fed to the cell after bubbling it through water for humidification. All the gas lines were thermostated at $75^{\circ} \mathrm{C}$ in order to prevent water condensation and purged with nitrogen before each experiment. Humidified hydrogen was fed into the anode side through 5 parallel channels of $0.1 \mathrm{~cm} \times 0.1$ $\mathrm{cm} \times 30 \mathrm{~cm}$, mechanized on the support plates, and the hydrogen flow was adjusted by means of mass flow controllers. Unreacted hydrogen was collected at the anode outlet and its humidity was measured by a probe Vaisala HUMICAP ${ }^{\circledR}$ humidity and temperature transmitter HMT330, also thermostated at $75^{\circ} \mathrm{C}$. At the cathode, the inlet was closed and a condenser unit was placed at the outlet to remove excess water from the high-pressure hydrogen flow. Downward the condenser unit, a pressure regulator Brooks ${ }^{\circledR}$ SLA5820s regulated the discharge pressure of hydrogen.

The MEAs were supplied by Ion Power. Two kinds of Nafion membranes were tested: (i) Nafion XI of thickness $25 \mu \mathrm{m}$ and (ii) Nafion 117 of thickness $175 \mu \mathrm{m}$. Gas diffusion layers (GDLs) Sigracet ${ }^{\circledR}$ (thickness $240 \mu \mathrm{m}$ ) and a gold-coated titanium porous transfer layer (PTL) with a pore size of $5 \mu \mathrm{m}$ and thickness $1 \mathrm{~mm}$ were used at the cathode and at the anode side, respectively. The use of a thick PTL instead of carbon papers on the anode side was essential to withstand the important pressure gradient over the cell. 


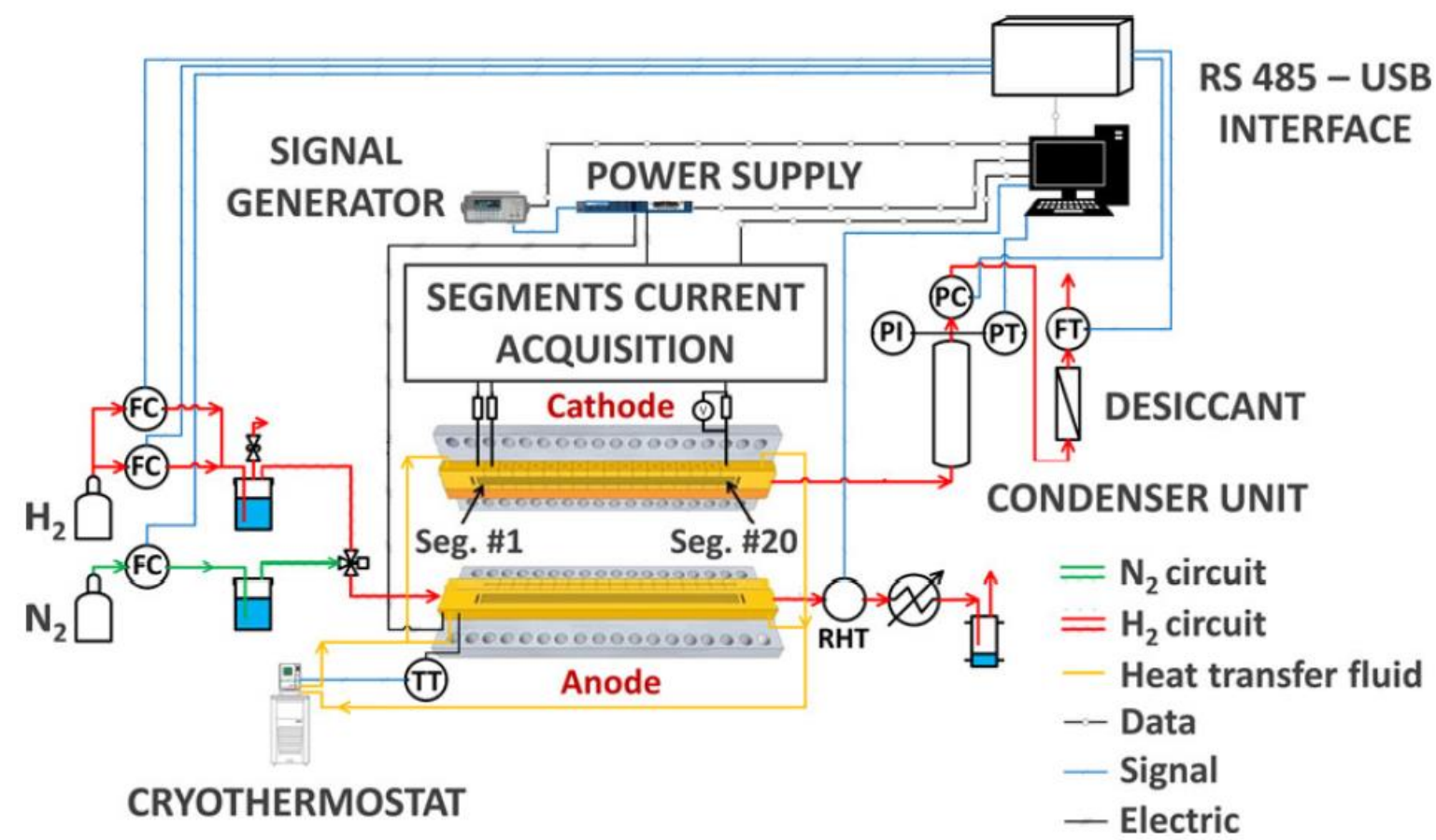

Figure 1: Schema of the experimental system used (the segmented EHC is in the central part of the Figure)

\section{Modeling}

Several transport and electrochemical phenomena occur in an EHC: (i) hydrogen and water diffusion across the PTL towards the MEA; (ii) hydrogen oxidation reaction on the anode, i.e. hydrogen "consumption"; (iii) water sorption at the membrane boundary; (iv) water and protons transport across the membrane; (v) water desorption at the opposite boundary of the membrane; (vi) high-pressure hydrogen formation at the cathode; (vii) hydrogen and water transport across the GDL towards the distribution channels; and (viii) heat transfer across the PTL, the MEA and the GDL. All these phenomena take place in the perpendicular direction to the MEA. In addition, a significant variation of water and hydrogen concentrations could be observed while the binary mixture flows along the gas channels, thus a one-dimensional (1D) model is not able to accurately describe the transport phenomena occurring in an EHC. 
For this reason, a pseudo-2D model was developed, which revealed to be more computationally efficient compared to $2 \mathrm{D}$ and $3 \mathrm{D}$ models ${ }^{[27]}$. A schema illustrating the principles of the pseudo2D model is shown in Figure 2. The transport phenomena were investigated in both directions, $x$ and $y$, i.e. the perpendicular direction to the MEA and the along-the-channels direction respectively. The EHC was divided into $k$ control volumes; hence the mass and energy balances along the $x$-direction were solved for each control volume. The hydrogen and water concentrations in the gas channel, $c_{H 2}{ }^{\text {chan }}(k)$ and $c_{H 2 O} \mathrm{O}^{\text {chan }}(k)$, were both evaluated through the mass transport equations in the $y$-direction, hence they were used as spatially boundary conditions for mass and energy balances along the $x$-direction. Thus, the only coupling between the two directions is achieved through boundary conditions.

In developing the pseudo-2D model, several simplifying assumptions were used:

i. Both hydrogen and water vapor were assumed to behave as ideal gases since the highest pressure and temperature reached by the experimental investigation were 32 bar and $60^{\circ} \mathrm{C}$, respectively. Indeed, the highest compressibility factor reached at these operating conditions, determined by using the REFPROP-7 software, is 1.02 . Thus, the deviation from the ideal behaviour is negligible;

ii. The partial pressure of water at the cathode side was assumed to be equal to the vapor pressure saturation at the operating temperature due to the high-pressure conditions. Indeed, the saturation pressure of water at $60^{\circ} \mathrm{C}$ is about 0.2 bar (calculated by the following Eq. (4)), whereas the total pressure at the cathode side is 32 bar. This means that, the highest molar fraction of vapour water achievable herein is $<0.006$. Thus the presence of liquid water was assumed at the cathode of the EHC in order to observe the total mass balance;

iii. Catalyst layers were assumed to act as thin interfaces where the electrochemical reactions occur without resistance to the mass or heat transfer [27]. 
In the following sections, every single part of the model is introduced and discussed.

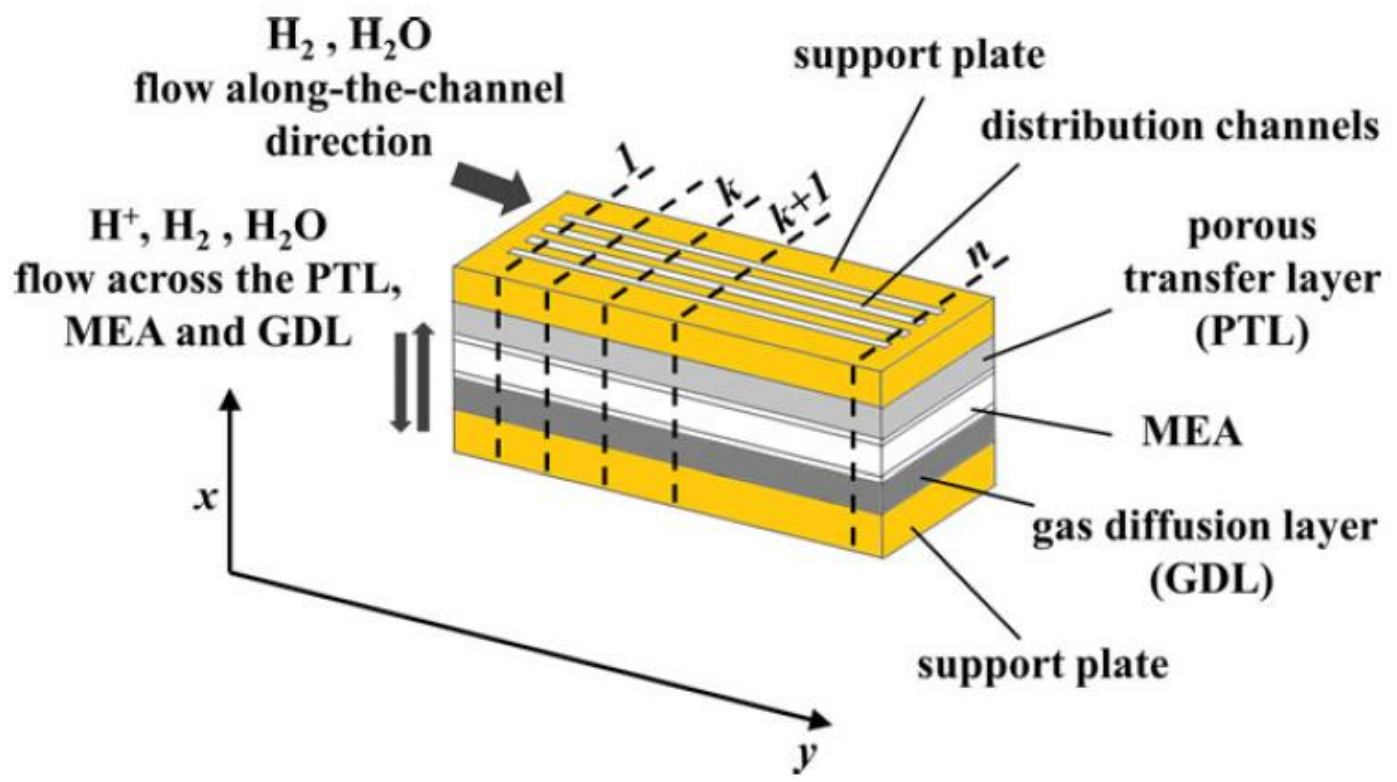

Figure 2: Graphical description of the pseudo-2D model

\subsection{Hydrogen and water transport along the gas channels}

The mass transport along the $y$-direction allows finding the hydrogen and water concentrations at the anode gas channels for each control volume $k$. These concentrations will be used as boundary conditions for the balances in the $x$-direction.

The hydrogen flow rate changes because of both hydrogen consumption on the anode and the permeation of the dissolved hydrogen molecules through the membrane, which is favored by the pressure gradient existing between the cathode and the anode side. Hence, the hydrogen flow rate generally decreases along the $y$-direction because of its consumption given by Faraday's law. The hydrogen flow rate $\dot{n}_{H_{2}}$ along the anode gas channels is given by: 


$$
\left\{\begin{array}{c}
\frac{d \dot{n}_{H_{2}}}{d y}=-p\left[\frac{i(y)}{2 F}-\dot{N}_{H_{2}, p e r m}\right] \\
\dot{n}_{H_{2},(y=0)}=S A \frac{I}{2 F}
\end{array}\right.
$$

where $p$ is the width of the active area, $i(y)$ is the local current density, $F$ is the Faraday constant (96485 $\left.\mathrm{C} \mathrm{mol}^{-1}\right), S$ is the stoichiometric ratio, $A$ is the active area, $I$ is the supplied current density to the EHC and $\dot{N}_{H_{2}, \text { perm }}$ is the hydrogen molar flux permeating across the membrane. We used the expression proposed by Schalenbach et al. [28] to describe the temperature dependence of $\dot{N}_{H_{2}, \text { perm }}$ :

$$
\dot{N}_{H_{2}, \text { perm }}=\varepsilon_{0} \exp \left(\frac{-E_{\varepsilon}}{k_{B} T}\right)\left(\frac{\left.{P_{H_{2}}{ }^{c a t}-P_{H_{2}}{ }^{a n}}_{x_{m e m b}}\right)}{x^{2}}\right)
$$

The permeation flux depends on the gas permeability, on the difference of hydrogen partial pressure at the cathode, $P_{H 2}{ }^{c a t}$, and the anode, $P_{H 2}{ }^{a n}$, and on the membrane thickness, $x_{m e m b} . k_{B}$ is the Boltzmann constant $\left(1.38 \cdot 10^{-23} \mathrm{~J} \mathrm{~K}^{-1}\right)$, whereas the value of the constants $\varepsilon_{0}$ and $E_{\varepsilon}$ were taken from the literature [29] and are listed in Table 1.

On the other hand, water concentration varies along the $y$-direction because of the mass transport across both the PTL and the membrane. The water flow rate, $\dot{n}_{\mathrm{H}_{2} \mathrm{O}}$, along the gas channels is given by:

$$
\left\{\begin{array}{c}
\frac{d \dot{n}_{\mathrm{H}_{2} \mathrm{O}}}{d y}=p \dot{N}_{\mathrm{H}_{2} \mathrm{O}}{ }^{P T L} \\
\dot{n}_{\mathrm{H}_{2} \mathrm{O}(y=0)}=S A \frac{I}{2 F} \frac{R H_{\text {chan }, \text { in }} p_{\text {sat }}(T)}{P_{\text {an }}-R H_{\text {chan }, \text { in }} p_{\text {sat }}(T)}
\end{array}\right.
$$

where $\dot{n}_{H_{2} \mathrm{O}}$ is the water flow rate along the distribution channels, $\dot{N}_{H_{2} \mathrm{O}}{ }^{P T L}$ is the water molar flux across the PTL, $R H_{\text {chan,in }}$ is the relative humidity of hydrogen at the gas channels inlet, $p_{\text {sat }}(T)$ and $P_{a n}$ are the saturation pressure and the total pressure on the anode side, respectively. $p_{\text {sat }}(T)$ was evaluated by using the Rankine's formula [30]: 


$$
p_{\text {sat }}(T)=P_{0} \exp \left(13.669-\frac{5096.23}{T+273.15}\right)
$$

where $P_{0}$ is the standard pressure.

Eq. (3) shows that drying of the hydrogen flow inwards the EHC is possible when there is an important water flow from the anode to the cathode; in contrast, the hydrogen flow is humidified when water flows is directed from the cathode to the anode side. Thus, the evolution of the relative humidity along the gas channels, $R H_{\text {chan }}$, can be evaluated by the following expression:

$$
R H_{\text {chan }}(y)=\frac{\dot{n}_{H_{2} O}}{\dot{n}_{H_{2} O}+\dot{n}_{H_{2}}} \frac{P_{a n}}{p_{s a t}(T)}
$$

\subsection{Hydrogen and water transport across the PTL}

The Stefan-Maxwell equation was used to predict hydrogen and water transport by convection and diffusion across the PTL. The Stefan-Maxwell equation is a generalization of the Fick's Law, and it is commonly used to describe the multicomponent convective and diffusive transports in a porous medium, and it was well demonstrated for a uniform velocity profile. The integrated form of Stefan-Maxwell equation [31] for the specific case of a binary flow of hydrogen and water is reported:

$$
\begin{gathered}
y_{\mathrm{H}_{2}}=\left(H R_{\text {chan }} \frac{P_{\text {sat }}}{P_{\text {an }}}-\frac{\dot{N}_{\mathrm{H}_{2} \mathrm{O}}{ }^{P T L}}{\dot{N}_{\mathrm{H}_{2}}{ }^{P T L}+\dot{N}_{\mathrm{H}_{2} \mathrm{O}}{ }^{P T L}}\right) * \exp \left(\frac{\left(\dot{N}_{\mathrm{H}_{2}}{ }^{P T L}+\dot{N}_{\mathrm{H}_{2} \mathrm{O}}{ }^{P T L}\right) * x_{P T L}}{c \mathcal{D}_{\mathrm{H}_{2}, \mathrm{H}_{2} \mathrm{O}} \text { eff }}\right) \\
-\frac{\dot{N}_{\mathrm{H}_{2} \mathrm{O}}{ }^{P T L}}{\dot{N}_{\mathrm{H}_{2}}{ }^{P T L}+\dot{N}_{\mathrm{H}_{2} \mathrm{O}}{ }^{P T L}}
\end{gathered}
$$

where $y_{\mathrm{H}_{2}}{ }^{P T L}$ is the molar fraction of hydrogen in the PTL, $\dot{\mathrm{N}}_{\mathrm{H}_{2}}{ }^{P T L}$ and $\dot{\mathrm{N}}_{\mathrm{H}_{2} \mathrm{O}}{ }^{P T L}$ are the molar flux of hydrogen and water across the PTL respectively, $c$ is the global molar concentration of the hydrogen/water mixture, $\mathcal{D}_{\mathrm{H}_{2}, \mathrm{H}_{2} \mathrm{O}}{ }^{\text {eff }}$ is the effective diffusion coefficient and $x_{P T L}$ is the PTL 
thickness. $\mathcal{D}_{\mathrm{H}_{2}, \mathrm{H}_{2} \mathrm{O}}$ eff was used instead of the intrinsic diffusion coefficient, $\mathcal{D}_{\mathrm{H}_{2}, \mathrm{H}_{2} \mathrm{O}}$ since the first one takes into account the PTL porosity [9], which affects the mass transport across the diffusion layer. Furthermore, the effect of temperature and pressure on $\mathcal{D}_{\mathrm{H}_{2}, \mathrm{H}_{2} \mathrm{O}}{ }^{\text {eff }}$ was considered as well [32] trough:

$$
\mathcal{D}_{H_{2}, H_{2} 0}{ }^{\text {eff }}(T, P)=\mathcal{D}_{H_{2}, H_{2} 0}{ }^{0}\left(T^{0}, P^{0}\right) \frac{P^{0}}{P}\left(\frac{T}{T^{0}}\right)^{3 / 2} \cdot \varepsilon_{P T L}{ }^{3 / 2}
$$

where $\mathcal{D}_{\mathrm{H}_{2}, \mathrm{H}_{2} \mathrm{O}}{ }^{0}$ is the diffusion coefficient evaluated at a specific temperature, $T^{0}=303 \mathrm{~K}$, and pressure, $P^{0}=1$ bar $^{[33]}$ and $\varepsilon$ is the porosity of the PTL. Eq. (7) shows that the higher the system temperature and $\varepsilon$ the higher the $\mathcal{D}_{\mathrm{H}_{2}, \mathrm{H}_{2} \mathrm{O}}{ }^{e f f}$.

\subsection{Water transport across the membrane}

In order to ensure optimum compression performances, a good hydration level of the membrane is required, since its protonic conductivity is enhanced when the membrane is saturated with water. Hence, protons cross the membrane in the hydrated form: $\mathrm{H}_{2 \zeta+l} \mathrm{O}_{\zeta}^{+}$, where $\zeta$ is the electro-osmosis coefficient. Membrane hydration is a key factor for water management in an EHC, and it can be evaluated by using the equation proposed by Springer and Zawodzinski [34]:

$$
\lambda=0.043+17.81 a-39.85 a^{2}+36 a^{3}
$$

where $a$ is the water activity and $\lambda$ is the membrane water content, defined as the number of water molecules per sulfonic acid site. $a$ can be defined by the ratio partial water pressure/vapor water pressure, at the same temperature. Eq. (8) was derived for the Nafion 117 membrane at $30^{\circ} \mathrm{C}$, but it has been applied also to temperatures as high as $60^{\circ} \mathrm{C}[35,36]$. According to the assumption 2, we considered that the cathode side is saturated with water and then $a=1$ and $\lambda$ $=14$ as boundary conditions at the membrane-cathode interface. Actually, Schroder paradox 
[37] states that $\lambda$ can be higher than 14, therefore the final value depends on both the pretreatment process and the mechanical constraints.

Water transport across the membrane occurs via two main mechanisms: electro-osmosis and diffusion. The electro-osmosis flux, from anode to cathode, takes place when water molecules are dragged across the membrane by the protons because of the electrostatic attraction. On the other hand, water diffusion, from cathode to anode, occurs as a consequence of the water concentration gradient across the membrane. In the present model, the global water flux across the membrane, $\dot{\mathrm{N}}_{\mathrm{H}_{2} \mathrm{O}}{ }^{m e m b}$, was supposed to be positive when directed from the anode to the cathode, and it can be evaluated by using the following equation:

$$
\dot{N}_{\mathrm{H}_{2} \mathrm{O}}{ }^{m e m b}=\zeta \frac{i(y)}{F}-D_{\mathrm{H}_{2} \mathrm{O}}{ }^{m e m b} \frac{\rho_{d r y}}{E W} \frac{d \lambda}{d x}
$$

where $\zeta$ is the electro-osmotic drag coefficient, $i(y)$ is le local current density, $\rho_{d r y}$ is the dry membrane density, $E W$ is the membrane equivalent weight and $D_{H 2 O}{ }^{\text {memb }}$ is the diffusion coefficient of water across the membrane .

$\zeta$, defined as the number of water molecules dragged per proton, was considered as constant in the present work. On the other hand, the variation of $D_{H 2 O}{ }^{m e m b}$ with respect to both $\lambda$ and $T$ was modeled by using the following expression from [38]:

$$
\begin{aligned}
\mathcal{D}_{H_{2} O}{ }^{m e m b}= & \left(5.1-0.66 \lambda+5.210^{-2} \lambda^{2}\right. \\
& \left.-1.310^{-3} \lambda^{3}\right) \cdot 10^{-6} \exp \left[2416\left(\frac{1}{303}-\frac{1}{T}\right)\right]
\end{aligned}
$$

According to these assumptions, the following equation for $\dot{\mathrm{N}}_{\mathrm{H}_{2} \mathrm{O}}{ }^{m e m b}$ was obtained by integrating Eq. (9): 


$$
\begin{aligned}
\dot{N}_{\mathrm{H}_{2} \mathrm{O}}^{m e m b}=\zeta & \frac{i(y)}{F} \\
& -\frac{\rho_{\text {dry }}}{E W x_{m e m b}}\left(5.1\left(\lambda_{\text {cat }}-\lambda_{a n}\right)-0.66 \frac{\left(\lambda_{c a t}{ }^{2}-\lambda_{a n}{ }^{2}\right)}{2}\right. \\
& +5.2 \cdot 10^{-2} \frac{\left(\lambda_{c a t}{ }^{3}-\lambda_{a n}{ }^{3}\right)}{3}-1.3 \\
& \left.\cdot 10^{-3} \frac{\left(\lambda_{c a t}{ }^{4}-\lambda_{a n}{ }^{4}\right)}{4}\right) \cdot 10^{-6} \cdot \exp \left[2416\left(\frac{1}{303}-\frac{1}{T}\right)\right]
\end{aligned}
$$

where $\lambda_{c a t}$ and $\lambda_{a n}$ are the membrane water content at the cathode and at the anode side, respectively, and $x_{m e m b}$ is the membrane thickness.

\subsection{Charge}

The voltage to be supplied to the EHC, $E$, is given by the following equation [10]:

$$
E=\frac{R T}{2 F} \ln \left(\frac{P_{c a t}}{P_{a n}}\right)+\frac{R T}{2 \alpha_{0, a n} F} \ln \left(\frac{i}{i_{0, a n}}\right)+\frac{R T}{2 \alpha_{0, c a t} F} \ln \left(\frac{i}{i_{0, c a t}}\right)+R_{e l} i
$$

where $\alpha_{0, \text { an }}$ and $\alpha_{0, c a t}$ are the charge transfer coefficient for the hydrogen oxidation and reduction, respectively; and, $i_{0, a n}$ and $i_{0, c a t}$ are the exchange current density for the anode and the cathode reaction, respectively. $R_{e l}$ incorporates: (i) the protonic resistance of the membrane, $R_{m e m b}$; (ii) the ionic and electronic resistance of the electrodes; and (iii) the contacts and cell hardware resistances. The first term of Eq. (12) is the Nernst voltage, which indicates the minimum voltage to be applied to the system in order to achieve the desired compression ratio. The second and the third terms are the anode and the cathode overpotentials, which can be defined as the potential losses due to the kinetics of the reaction. Finally, the last term of Eq. (12) indicates the Ohmic losses, which are mainly governed by $R_{m e m b}$ and is roughly given by the membrane 
thickness/ membrane protonic conductivity ratio, $x_{m e m b} / \sigma_{m e m b}$. The following expression for $\sigma_{m e m b}$ was used [34]:

$$
\sigma_{m e m b}=(5.139 \lambda-3.26) \cdot 10^{-3} \exp \left(1263\left(\frac{1}{303}-\frac{1}{T}\right)\right)
$$

Eq. (13) clearly shows that the higher $\lambda$ the higher its $\sigma_{m e m b}$. Thus, high water content is necessary in order to decrease the protonic resistance of the membrane. Eq. (13) is valid for $\lambda$ $>0.63$ (which gives $\sigma_{\text {memb }}>0$ ). For $\lambda<0.63, \sigma_{\text {memb }}$ was set to $10^{-10} \mathrm{~S} \mathrm{~cm}^{-1}$ and not to zero to prevent numerical difficulty.

Precisely, the global $R_{m e m b}$ is given by the following expression:

$$
R_{m e m b}=\int_{0}^{x_{m e m b}} \frac{d x}{\sigma(\lambda(x), T)}
$$

To solve the previous definite integral, the trapezoidal rule was used, which gives an average value between the protonic resistance evaluated at the anode and that evaluated at the cathode:

$$
R_{m e m b}=\frac{x_{m e m b}}{2}\left(\frac{1}{\sigma\left(\lambda_{c a t}, T_{c a t}\right)}+\frac{1}{\sigma\left(\lambda_{a n}, T_{a n}\right)}\right)
$$

\subsection{Heat transfer and temperature evolution}

The one-dimensional heat transfer in the through-plane direction was described using the analogy with an electrical circuit, and composed by the thermal resistances and heat sources or sinks (Figure 3).

The following three heat sources were considered: 
i. Heat conduction: the heat conduction occurring across the PTL, the membrane and the GDL was modeled by using the Fourier law. Thus, a thermal resistance was introduced for each layer and it was defined as the layer thickness/ thermal conductivity ratio.

ii. Water condensation/evaporation: water vapor is present along the PTL, liquid water is present along the membrane and the GDL contains both liquid and vapor water. Thus, sorption/desorption phenomena may occur on the membrane layer interfaces with PTL and GDL. Water condensation occurs on the anode/membrane interface and the amount of released heat can be obtained by the product between the water flow across the membrane (Eq. (10)) and the heat of sorption, which can be assimilated to the latent heat of water vaporization [39]. However, evaporation was not considered on the cathode/membrane interface because high pressure almost avoids water vaporization, only a small amount of water could vaporize. Therefore, saturation conditions all over the cathode side were assumed.

iii. Joule effect: heat is released in the membrane because of its resistance, which is the main factor causing the increase of the temperature along the membrane.

The contribution of the activation overpotential to the heat production was not taken into account in our model, as it is negligible in an EHC. Indeed, both the hydrogen oxidation and reduction reactions are highly reversible [13]. Hence, we assumed that the temperature gradients were only due to the above-stated heat sources, as both support plates are initially at the same temperature on the low and on the high-pressure compartments. 


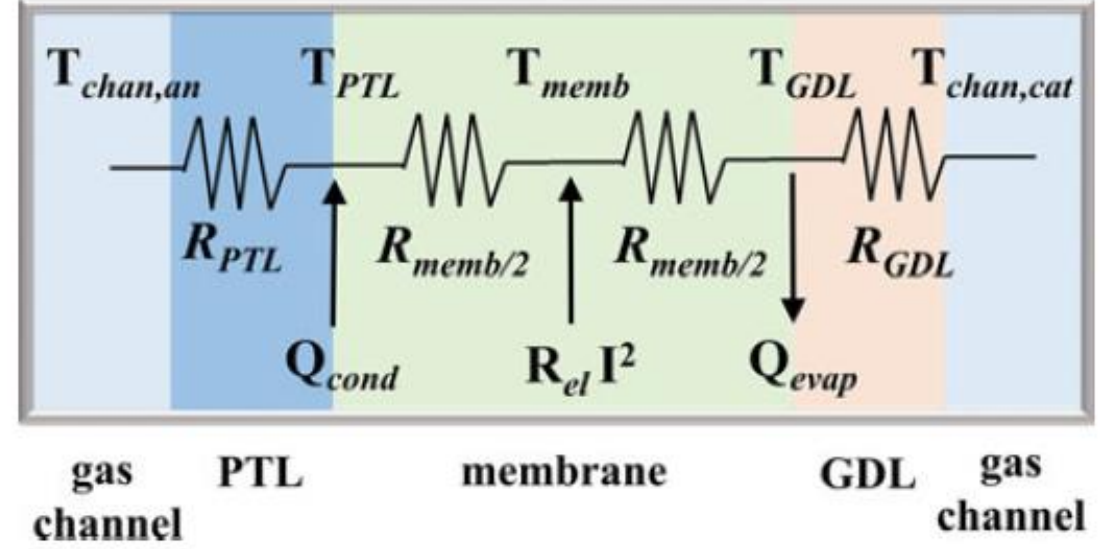

Figure 3: Equivalent electric circuit for the heat transfer along the $\mathrm{x}$ direction

\subsection{Implementation of the numerical method}

The coupled equations of the above-presented pseudo-2D model were solved by using the Matlab software. Table 1 contains all the parameters used for the numerical simulations. Most of the parameters are related to the cell geometry and to the dimensions of every single component, i.e. the PTL, the membrane and the GDL. The thermal conductivity of the PTL was determined from the measurement of the heat capacity, using a calorimeter (Setaram ${ }^{\circledR} \mu \mathrm{dSc} 3$ ), and from the measurement of the thermal diffusivity, using the flash method (equipment) [40]. A porosity of $28 \%$ was determined for the PTL, taking into account the density of the bulk and of the porous titanium. The parameters for which reliable estimates were available in the literature were set and also listed in Table 1, e.g. the thermal conductivity of the membrane and the parameters related to the hydrogen permeation across the membrane. On the other hand, parameters that could not be reliably estimated and were difficult to be directly measured were obtained by fit of data taking into account both the boundary conditions and the experimental results. It is the case of the electro-osmotic drag coefficient $\zeta$, which was estimated by considering both the measured cell voltage and the $R H$ of the hydrogen flow measured at the 
anode outlet. For all the simulations, a value of $\zeta$ around 0.9 has been adjusted, in agreement with experimental data from literature [41].

Table 1 - Parameters used in the present numerical model

\begin{tabular}{|c|c|c|c|}
\hline Parameter / units & symbol & value & source \\
\hline Activation Energy - Hydrogen Permeation / J & $E_{\varepsilon}$ & $4.28 \cdot 10^{-20}$ & [29] \\
\hline Active area $/ \mathrm{cm}^{2}$ & $A$ & 30 & This study \\
\hline Active area width / cm & $p$ & 1 & This study \\
\hline Anode pressure / bar & $P_{a}$ & 1 & This study \\
\hline Cathode pressure / bar & $P_{c}$ & 32 & This study \\
\hline Dry membrane density $/ \mathrm{kg} \mathrm{cm}^{-3}$ & $\rho_{d r y}$ & $2 \cdot 10^{-3}$ & From ${ }^{[43]}$ \\
\hline Diffusion coefficient $/ \mathrm{cm}^{2} \mathrm{~s}^{-1}$ & $D_{H 2, H 2 O}{ }^{0}$ & $1.64 \cdot 10^{-1}$ & [43] \\
\hline Electro-osmotic drag coefficient / - & $\zeta$ & 0.9 & This study \\
\hline GDL thermal conductivity / $\mathrm{W} \mathrm{cm}^{-1} \mathrm{~K}^{-1}$ & $k_{G D L}$ & $3 \cdot 10^{-3}$ & [44] \\
\hline GDL thickness / cm & $x_{G D L}$ & 0.48 & This study \\
\hline Heat of sorption / $\mathrm{J} \mathrm{mol}{ }^{-1}$ & $Q_{\text {sorp }}$ & $4.05 \cdot 10^{4}$ & This study \\
\hline $\mathrm{H}_{2}$ permeation pre-factor $/ \mathrm{mol} \mathrm{cm} \mathrm{cm}^{-1} \mathrm{~s}^{-1} \mathrm{bar}^{-1}$ & $\varepsilon_{0}$ & $2.53 \cdot 10^{-7}$ & [29] \\
\hline Membrane equivalent weight $/ \mathrm{kg} \mathrm{mol}^{-1}$ & $E W$ & 1.1 & [43] \\
\hline Membrane thermal conductivity / $\mathrm{W} \mathrm{cm} \mathrm{cm}^{-1} \mathrm{~K}^{-1}$ & $k_{m e m b}$ & $3.4 \cdot 10^{-3}$ & [43] \\
\hline PTL porosity / \% & $\varepsilon_{P T L}$ & 28 & This study \\
\hline PTL thermal conductivity / $\mathrm{W} \mathrm{cm}^{-1} \mathrm{~K}^{-1}$ & $k_{P T L}$ & $8 \cdot 10^{-2}$ & This study \\
\hline PTL thickness / cm & $x_{P T L}$ & 0.1 & This study \\
\hline Stoichiometric ratio / - & $S$ & 1.25 & This study \\
\hline
\end{tabular}




\section{Results and discussion}

\subsection{Overview of the EHC performances}

Our results confirmed that the isothermal compression of hydrogen can be achieved by using an EHC. Figure 4 shows the predicted average temperature of the anode, the membrane and the cathode, as a function of the supplied current density. The temperature difference between the membrane and the supporting plates, which were kept at $60^{\circ} \mathrm{C}$, was lower than $0.3^{\circ} \mathrm{C}$ for low supplied current densities and never higher than $1^{\circ} \mathrm{C}$. Thus the EHC system ensured an isothermal hydrogen compression, which is one of its most important advantages over any other hydrogen compression system available nowadays. Isothermal compression requires low compression work at very high pressure contrarily to an adiabatic process [42], thus high efficiency can be reached.

The theoretical compression work, $W_{t h}$, of an EHC can be written by considering the compression as isothermal without any voltage losses [42]:

$$
W_{t h}=\frac{R T}{M} \log \left(\frac{P_{c}}{P_{a}}\right)
$$

Eq. (16) can be rewritten by using $E_{\text {Nernst }}$ as previously shown in Eq. (12):

$$
W_{t h}=\frac{E_{\text {Nernst }} \cdot I}{M \frac{I}{2 F}}
$$

where $M$ is the molar mass of hydrogen. Thus, the efficiency of an EHC can be evaluated by considering the real compression work, $W_{\text {real }}$, which takes into account the increase of both the cell voltage, due to the overpotentials and the ohmic resistance, and the current density due to the hydrogen permeation across the membrane $\left(I_{\text {loss }}\right)$ :

$$
\eta=\frac{W_{\text {th }}}{W_{\text {real }}}=\frac{E_{\text {Nernst }}}{E} \cdot \frac{I-I_{\text {loss }}}{I}
$$


According to this definition, compression efficiency up to $60 \%$ can be reached at low pressure ( $<100$ bar) with an operating current density, $I$, of around $1 \mathrm{~A} \mathrm{~cm}^{-2}$ and $I_{\text {loss }}=0.04 \mathrm{~A} \mathrm{~cm}^{-2}$. However, the membrane thickness severely affects the EHC compression efficiency. A compression efficiency of $37 \%\left(3.55 \mathrm{kWh} \mathrm{kg}^{-1}\right)$ was calculated considering Nafion 117 , whereas $53 \%\left(2.5 \mathrm{kWh} \mathrm{kg}^{-1}\right)$ was calculated considering a thinner membrane as Nafion XL, at the same operating conditions $\left(T=60^{\circ} \mathrm{C}, I=0.33 \mathrm{~A} \mathrm{~cm}^{-2}, R H_{\text {chan, } \text { in }}=90 \%\right.$ and $P_{c}=32$ bar $)$. The efficiency achievable by using an EHC was proved to be higher than that generally reached by using a hydrogen mechanical compressor [10].

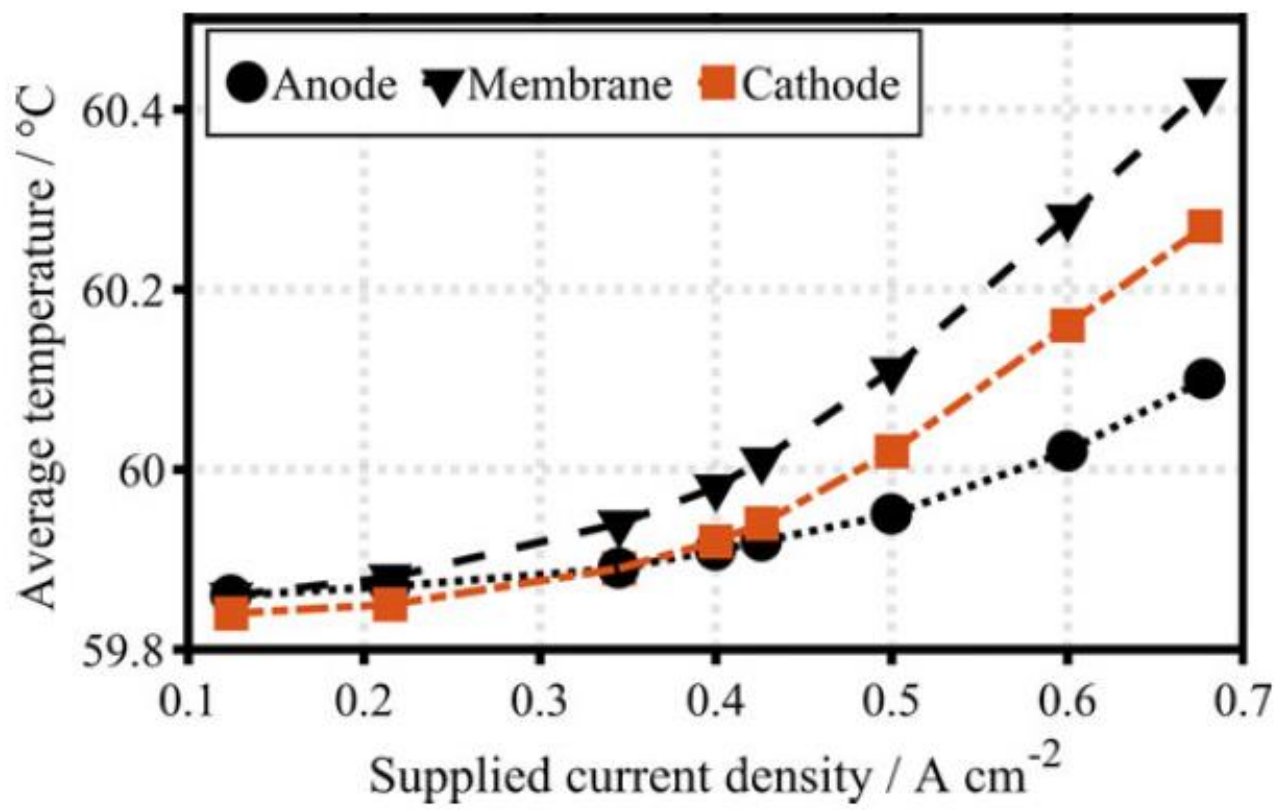

Figure 4: Average temperature of the anode, the membrane and the cathode of an EHC as a function of the supplied current densities (Nafion 117, $R H_{c h a n, i n}=90 \%$ and $P_{c}=32$ bar) 


\subsection{Effect of the current density applied to the EHC}

Figure 5 shows the current density distribution over the EHC depending on the applied current density. The current density distribution remained uniform until the applied current density was fixed at $0.66 \mathrm{~A} \mathrm{~cm}^{-2}$. At this value, the local current density was higher at the anode inlet than at the anode outlet $\left(0.75 \mathrm{~A} \mathrm{~cm}^{-2}\right.$ vs. $\left.0.65 \mathrm{~A} \mathrm{~cm}^{-2}\right)$ due to the unbalanced water flux across the membrane. In fact, a non-uniform water concentration profile was set along the membrane by the more important contribution of the electro-osmotic flux from the anode to the cathode with respect to the water back diffusion flux, in full agreement with Eq. (9). Indeed, the higher the current density applied to the system the higher the contribution of the water transport by electro-osmosis, which produced the decrease of the water concentration along the gas channel. Hence, the contribution of the water back diffusion became important close to the anode outlet, stabilizing the current density distribution and the hydration level of the membrane. On the other hand, when a lower current density was applied to the $\mathrm{EHC}\left(0.16 \mathrm{~A} \mathrm{~cm}^{-2}\right.$ or $\left.0.33 \mathrm{~A} \mathrm{~cm}^{-2}\right)$, a quite homogeneous distribution of the local current densities was obtained probably due to the equilibrium between the electro-osmotic and water diffusion flux all over the EHC.

The developed pseudo-2D model shown in Section 3 also proved that the stability of the current density strictly depends on the local water content of the membrane. Our model succeded in describing the decrease of the current density along the EHC at $0.66 \mathrm{~A} \mathrm{~cm}^{-2}$ as well as its stability when supplying a low current density, as shown in Figure 5. Indeed, the sum of squared residuals was lower than $10^{-6}$ in all the cases. 


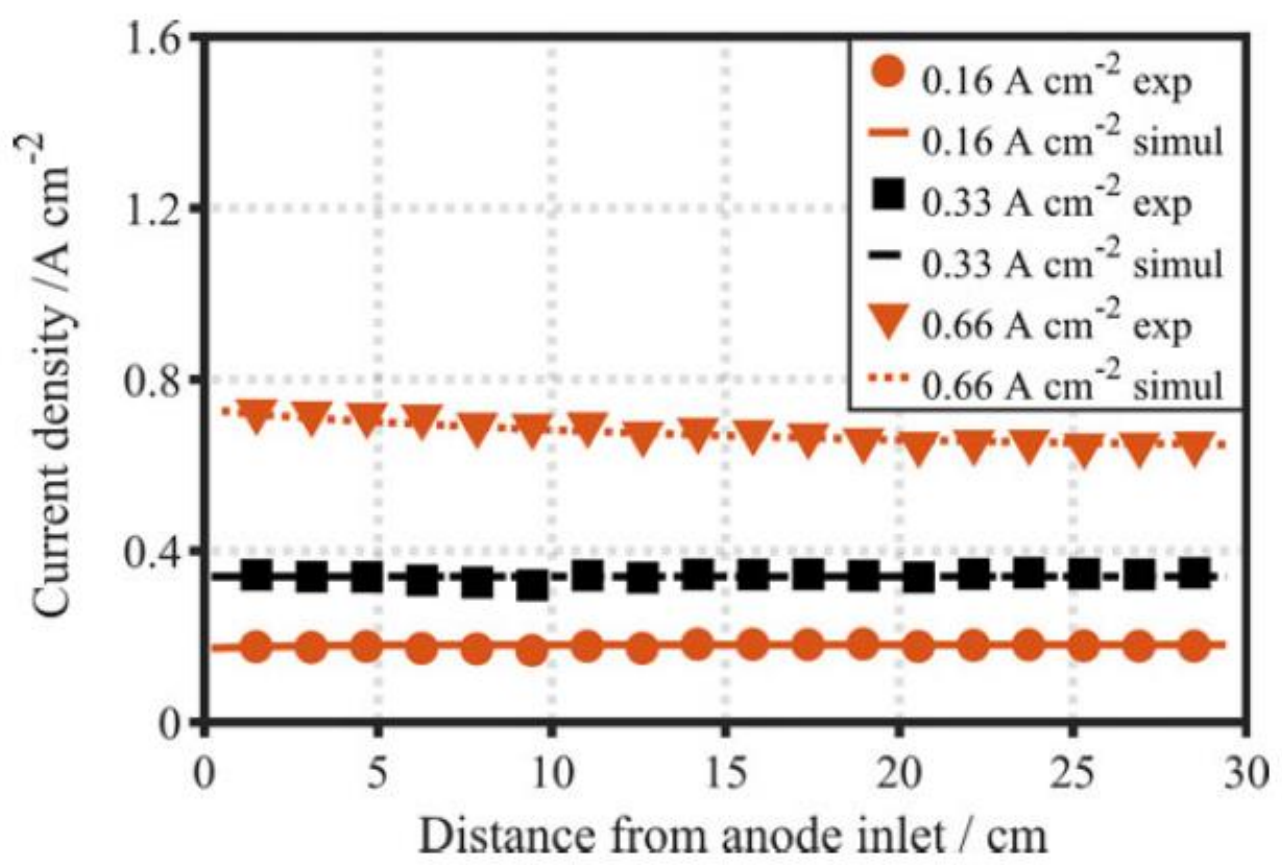

Figure 5: Distribution of the local current densities in an EHC as a function of the distance from the anode inlet when considering Nafion 117 for different supplied current densities $\left(T=60^{\circ} \mathrm{C}, R H_{\text {chan,in }}=90 \%\right.$ and $P_{c}=32$ bar $)$

Table 2 shows that the higher $I$ the higher $E$ according to Eq. (12), and some measured and predicted physical quantities when considering the three current densities used in Figure 5 are also listed. The model gave a good prediction of the relative humidity at the anode outlet. Indeed, it predicted a $R H$ equal to $55 \%$ when supplying $0.66 \mathrm{~A} \mathrm{~cm}^{-2}$, whereas the value measured by the humidity probe was $56 \%$. The $R H$ predicted for the case of $I=0.33 \mathrm{~A} \mathrm{~cm}^{-2}$ was 5\% lower than that measured experimentally. Moreover, both the experimental and predicted values of the $R H$ at the anode outlet and the calculated $\lambda_{a n}$ confirm that a significant dehydration of the membrane occurred when increasing the current density. Indeed, $\lambda_{a n}$ was found to be equal to 3.95 when supplying $0.66 \mathrm{~A} \mathrm{~cm}^{-2}$, whereas 11.16 was obtained in the case of $I=0.16 \mathrm{~A} \mathrm{~cm}^{-2}$, meaning that the average water content on the anode is significantly low at relatively high current densities. The occurred dehydration is the reason of the increase in the 
total resistance of the EHC, by more than $50 \%$ when increasing the current density from 0.16 to $0.66 \mathrm{~A} \mathrm{~cm}^{-2}$.

Table 2 - Experimental and predicted parameters in an EHC for three different current densities (Nafion $117, T=60^{\circ} \mathrm{C}, R H_{\text {chan, } \text {, }}=90 \%$ and $P_{c}=32$ bar )

\begin{tabular}{|l|c|c|c|}
\hline & \multicolumn{2}{|c|}{ Parameter values as a function of $I / \mathrm{A} \mathrm{cm}^{-2}$} \\
\hline Cell voltage $E$ / V (experiment) & 0.16 & 0.33 & 0.66 \\
\hline$R H$ at the anode outlet / \% & 0.0962 & 0.137 & 0.345 \\
(experiment/model) & $98 / 100$ & $92 / 97$ & $55 / 56$ \\
\hline Average water content on the anode $\lambda_{\text {an }} /$ - & 11.16 & 8.54 & 3.95 \\
(model) & & & \\
\hline Total resistance of the EHC / $\Omega \mathrm{cm}^{2}$ & $1.99 \cdot 10^{-1}$ & $2.35 \cdot 10^{-1}$ & $4.39 \cdot 10^{-1}$ \\
(experiment) & & & 10.3 \\
\hline Hydrogen pumped / NL ${ }^{-1}$ (experiment) & 2.6 & 5.2 & $14 \%$ \\
\hline Efficiency / \% (experiment) & $56 \%$ & $37 \%$ & \\
\hline
\end{tabular}

Figure 6 shows both the experimental cell voltages and the predicted polarization curve describing the $I-V$ relationship in the EHC. The cell voltage increased sharply with the global current density due to the significant increase in the total resistance of the $\mathrm{EHC}$ at high current density, as previously described and in agreement with Eq. (14).

Figure 7 shows the predicted evolution of the relative humidity along both the gas channel and the anode-membrane interface for two different current densities, 0.33 and $0.66 \mathrm{~A} \mathrm{~cm}^{-2}$. At 0.66 $\mathrm{A} \mathrm{cm}^{-2}$, the decrease of $R H$ is more significant along the gas channel than along the anode, both 
reaching the same value close to the EHC outlet due to the equilibration of the electro-osmosis and the water diffusion flux. In addition, the $R H$ at the EHC inlet is much higher at the gas channel than at the anode. At $0.33 \mathrm{~A} \mathrm{~cm}^{-2}$, an opposite behavior is observable. Both behaviors are due to the resistance to the water transfer exhibited by the PTL. In fact, the PTL used in the present study comprised very small pores, with an average diameter of around $3 \mu \mathrm{m}$. Whereas small pores hinder water diffusion, the presence of large pores is harmful to the membrane, which is then poorly mechanically supported. Thus, an optimum value of the pore diameters exists, ensuring both an efficient mass transfer and good mechanical support.

The dramatic increase in the total resistance of the EHC caused a significant decrease in the overall efficiency. A global efficiency around 14\% was calculated by our model when $0.66 \mathrm{~A}$ $\mathrm{cm}^{-2}$ was supplied to the system, whereas $37 \%$ was obtained at $0.33 \mathrm{~A} \mathrm{~cm}^{-2}$ and $56 \%$ at $0.16 \mathrm{~A}$ $\mathrm{cm}^{-2}$ (see Table 2). Low current densities allow obtaining higher global efficiencies but the hydrogen flow rate at high-pressure is also reduced from 10.3 to $2.6 \mathrm{NL} \mathrm{h}^{-1}$ at 0.66 and $0.16 \mathrm{~A}$ $\mathrm{cm}^{-2}$, respectively. Therefore, a trade-off between the amount of high-pressure hydrogen produced and its efficiency is necessary when evaluating the performance of an EHC system. 


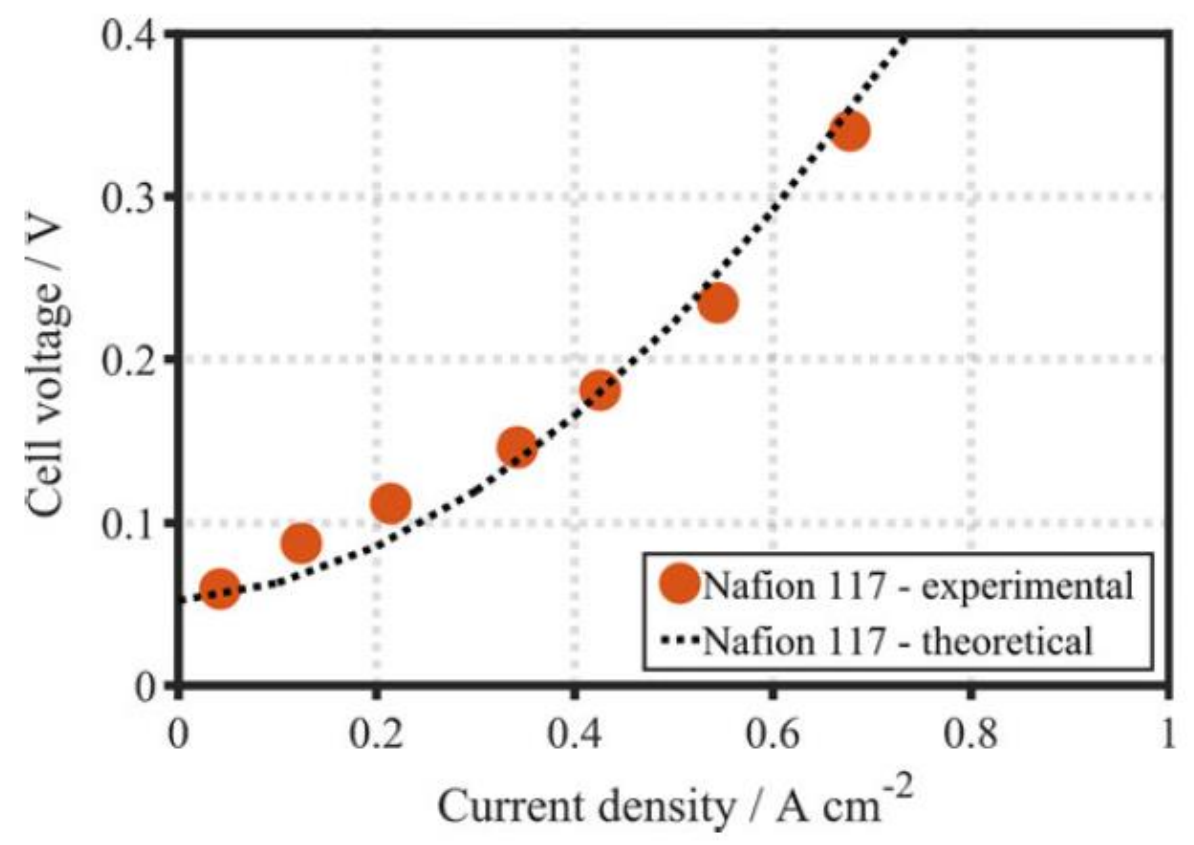

Figure 6: Experimental and predicted average polarization curves when considering Nafion 117 $\left(T=60^{\circ} \mathrm{C}, R H_{\text {chan, }, \text { in }}=90 \%\right.$ and $P_{c}=32$ bar $)$

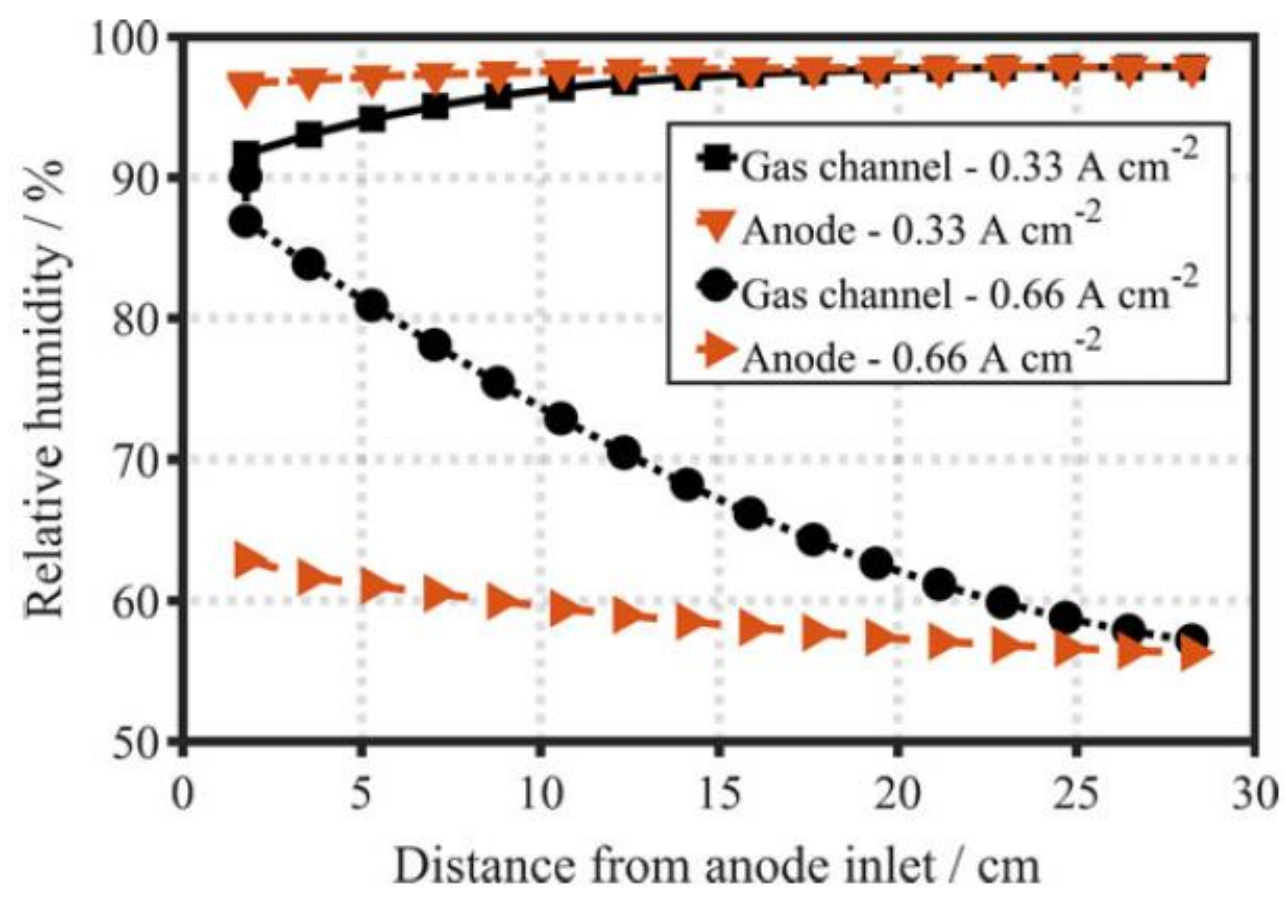

Figure 7 -Evolution of the relative humidity along the gas channels and at the anode-membrane interface of a EHC (Nafion $117, T=60^{\circ} \mathrm{C}, R H_{\text {chan, }, \text { in }}=90 \%$ and $P_{c}=32$ bar) 


\subsection{Effect of the relative humidity of the inlet hydrogen flow}

The effect of the hydrogen relative humidity at the inlet of the cell on the local current density distribution and on the resistance is presented in Figure 8 for $R H_{\text {chan, },}=30 \%$ and $90 \%$.

For $R H_{\text {chan,in }}=30 \%$, the local current density was around $0.2 \mathrm{~A} \mathrm{~cm}^{-2}$ close to the anode inlet and it slightly increased up to $0.23 \mathrm{~A} \mathrm{~cm}^{-2}$ in the first 7 centimeters; it sharply increased in the middle of the EHC becoming stable at around $0.43 \mathrm{~A} \mathrm{~cm}^{-2}$ at $23 \mathrm{~cm}$ from the anode inlet. This evolution is directly related to a decrease in the total resistance of the EHC, which was evaluated by the $I-V$ curves measured for each segment (see Figure 9). Indeed, the total resistance of the EHC decreased from $0.8 \Omega \mathrm{cm}^{2}$ to $0.4 \Omega \mathrm{cm}^{2}$ along the whole system, with a remarkable reduction of $50 \%$. It can be deduced that gradual hydration of the membrane occurred, contrarily to the behaviour observed in the previous Subsection 4.2. Indeed, the water flux due to the water back diffusion was higher than the electro-osmotic one at the first $10 \mathrm{~cm}$ of the EHC because of the dry inlet conditions herein. This led to a net water flux from the cathode to the anode which "consumed" water at the cathode and gave rise to unstable performances that cannot be explained by our modeling assumptions, which proved to give good predictions of experimental data once stationary conditions are reached. Liquid water may be supplied on the high-pressure side in order to prevent the cathode dehydration thus balancing the water transport across the membrane when low humidity hydrogen is fed to the EHC. However, this solution would clearly make the system more complex because it requires pumping water at high pressures.

For $R H_{\text {chan,in }}=90 \%$, the current density distribution along the EHC was quite uniform due to the fact that the membrane was uniformly hydrated. Nevertheless, the homogenous current density distribution shown in Figure 8 was obtained at relatively low current density, $0.33 \mathrm{~A}$ $\mathrm{cm}^{-2}$. 


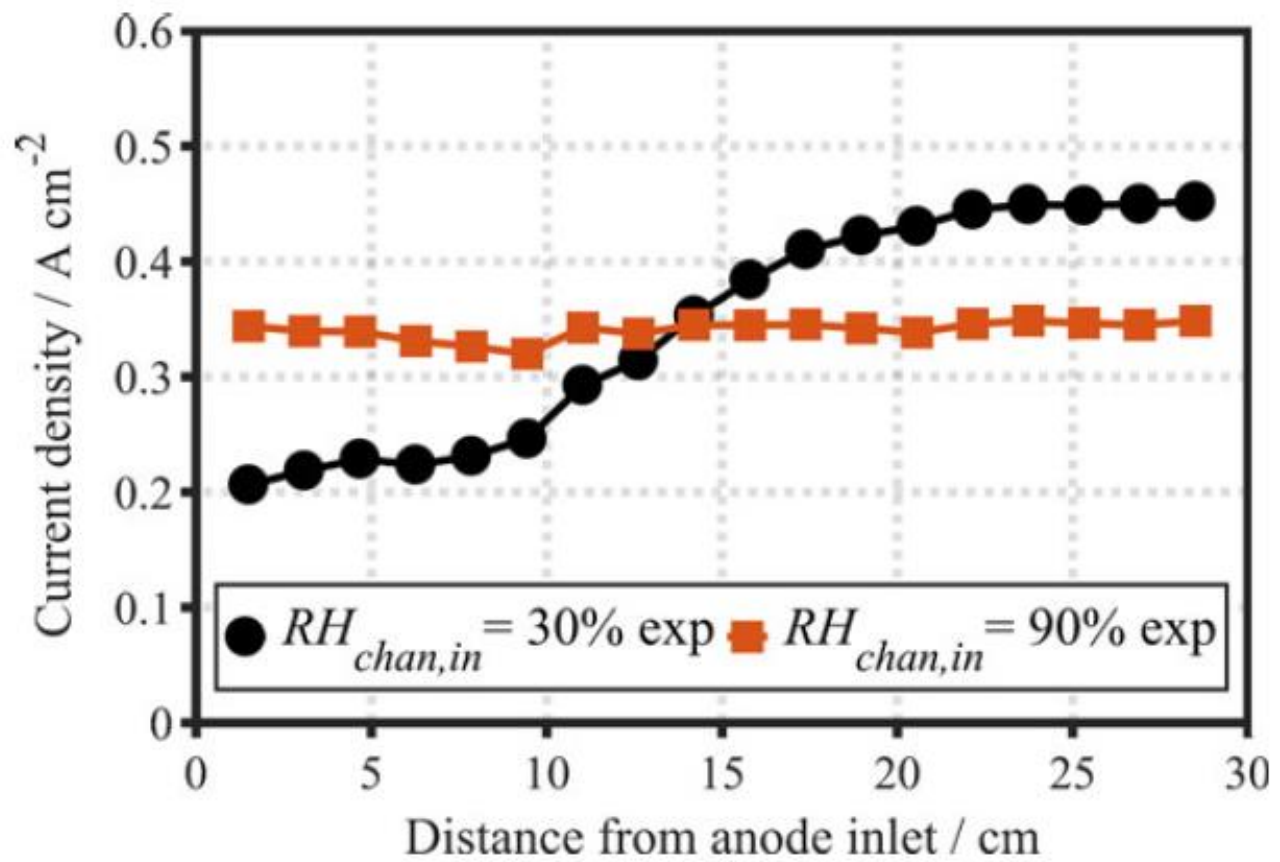

Figure 8: Experimental distribution of the current density in an EHC for different values of $R H_{\text {chan, in }}$ (Nafion $117, T=60^{\circ} \mathrm{C}, I=0.33 \mathrm{~A} \mathrm{~cm}^{-2}$ and $P_{c}=32 \mathrm{bar}$ )

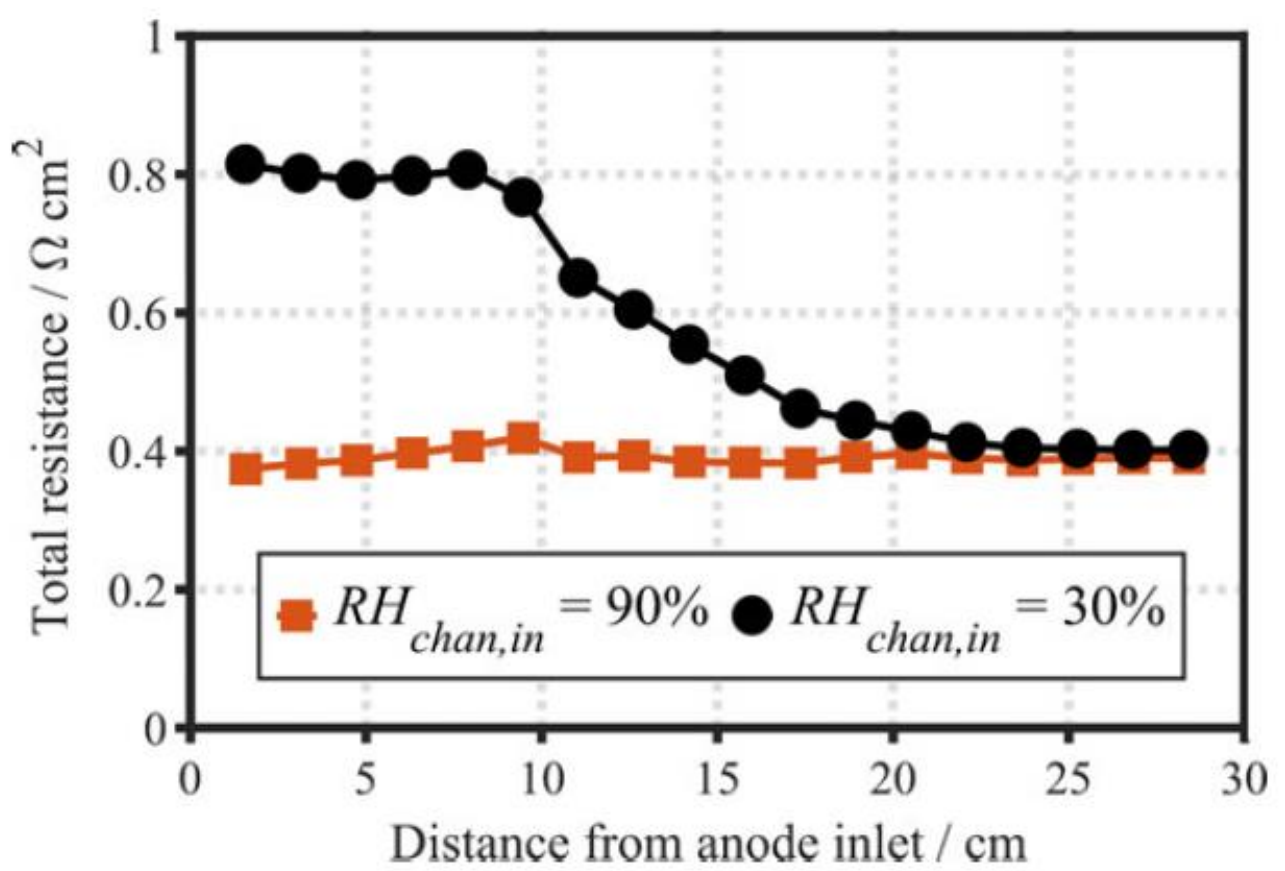

Figure 9: Distribution of overall resistance in an EHC for different values of $R H_{\text {chan, in }}$ (Nafion $117, T=60^{\circ} \mathrm{C}, I=0.33 \mathrm{~A} \mathrm{~cm}^{-2}$ and $\left.P_{c}=32 \mathrm{bar}\right)$ 


\subsection{Effect of the membrane thickness}

Figure 10 shows the experimental and predicted current density distribution along the EHC for two membranes: (i) Nafion XL - thickness $30 \mu \mathrm{m}$ and Nafion 117 - thickness $175 \mu \mathrm{m}$. When using Nafion XL, a slight increase of the current density was observed in the first segments of the cell while the current density slight decreased close to the anode outlet. The numerical simulation predicted that the behavior of both membranes should be identical, i.e., the local current density distribution is supposed to be quite stable all over the system since water should be uniformly transported across the membrane. The discrepancy between the predicted and experimental Nafion XL behavior could be explained by both the non-uniform clamping force, which led to non-uniform contact resistance, and the tightness differences between the extremities and the central part of the EHC. Indeed, the relative contribution of the contact resistance is generally higher when a thin membrane is used.

The membrane thickness significantly affects the hydrogen permeation induced by the pressure difference between the anode and the cathode. The permeation flux of hydrogen through the membrane was measured by supplying nitrogen to the anode side meanwhile high-pressure hydrogen was present on the cathode side. Once hydrogen permeated through the membrane, the oxidation reaction took place at the anode. Hence, the hydrogen permeation flux was correlated to an equivalent current density through the Faraday's Law $\left(I_{\text {loss }}\right)$. A permeation current density around $5.22 \mathrm{~mA} \mathrm{~cm}^{-2}$ was obtained when using Nafion 117 , whereas $45.31 \mathrm{~mA}$ $\mathrm{cm}^{-2}$ was obtained in the case of Nafion XL. Thus, the thicker is the membrane the lower is the hydrogen permeation, in agreement with Eq. (2). According to these results, Nafion 117 should be preferred to Nafion XL, since an important hydrogen permeation flux makes decreasing the compression efficiency (in agreement with Eq. (18)). Nevertheless, the efficiency loss associated with permeation through the membrane is negligible when compared to that associated with the proton resistance of the membrane for a pressure gradient of $32 \mathrm{bar}$. The 
advantage is clearly on the side of the thin membrane. In fact, a cell voltage of $0.137 \mathrm{~V}$ was supplied by using Nafion 117, whereas around $0.06 \mathrm{~V}$ were supplied by using Nafion XL when the global current density was $0.33 \mathrm{~A} \mathrm{~cm}^{-2}\left(T=60^{\circ} \mathrm{C}, R H_{\text {chan, } i n}=90 \%, P_{c}=32\right.$ bar $)$. In good agreement, Figure 11 shows that a linear $I-V$ relationship and high current density were achieved by using Nafion XL while worse performances were obtained by using Nafion 117 .

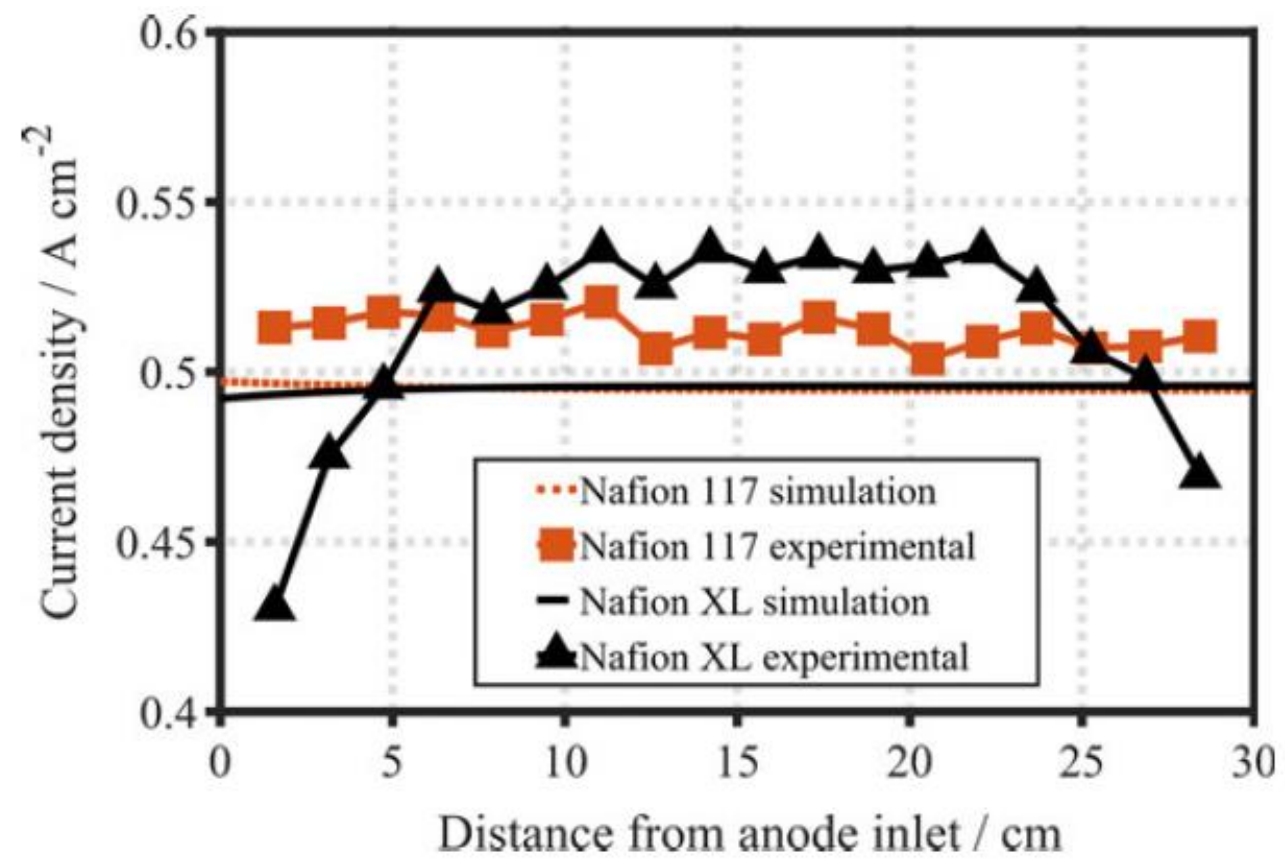

Figure 10: Distribution of the current density in an EHC for different membrane thickness $(T=$ $60^{\circ} \mathrm{C}, I=0.5 \mathrm{~A} \mathrm{~cm}^{-2}, R H_{\text {chan, },}=90 \%$ and $P_{c}=32$ bar) 


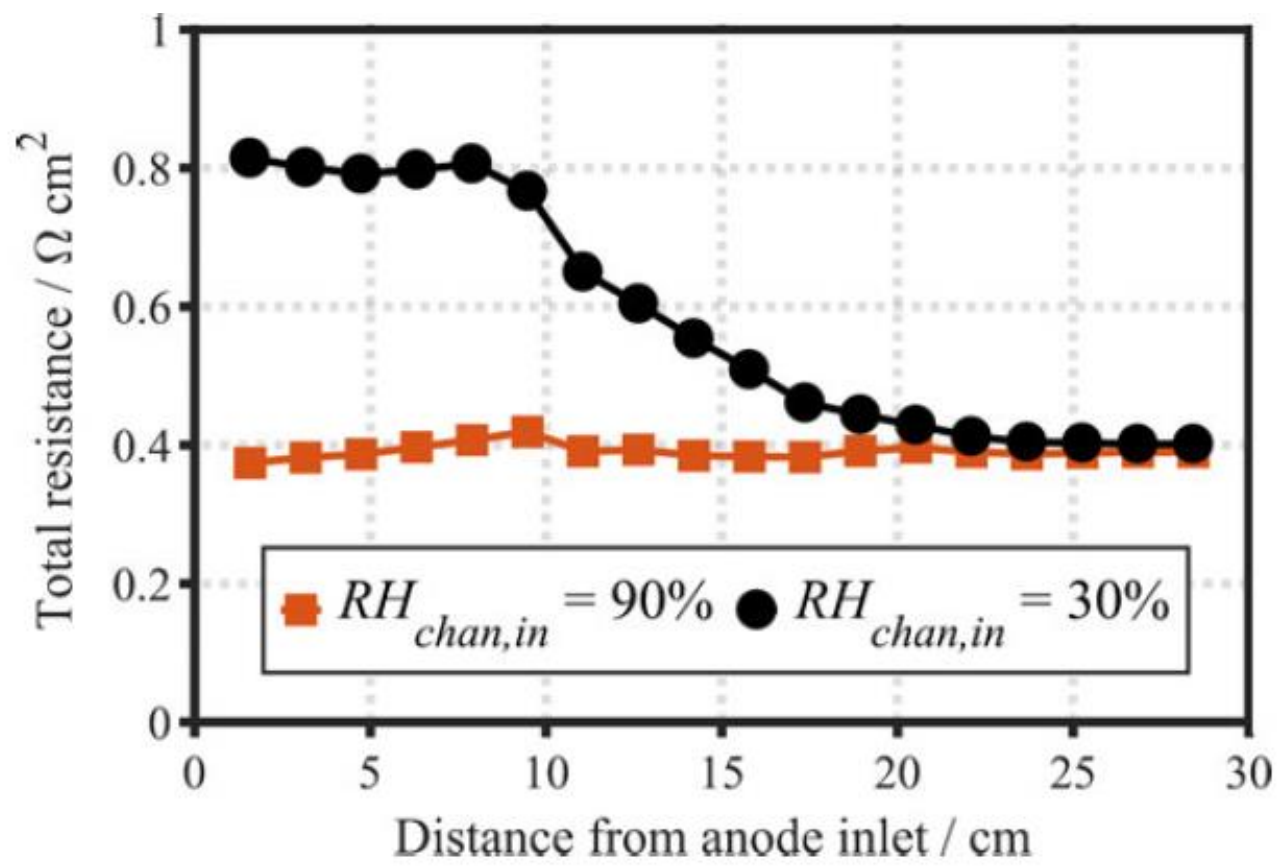

Figure 11: Measured and calculated polarization curves when using different membrane thickness $\left(T=60^{\circ} \mathrm{C}, R H_{\text {chan, } \text { in }}=90 \%\right.$ and $P_{c}=32$ bar $)$

\section{Conclusion}

In this study, the feasibility of hydrogen compression in an electrochemical system was proved. We got insight on the importance of water management to obtain high efficiencies by using an electrochemical hydrogen compressor (EHC) with a single $30 \mathrm{~cm}^{2}$ cell segmented into 20 parts. In this system, a pressure as high as 32 bar was achieved, and the compression process proved to be isothermal. The effects of the current density supplied to the system, the relative humidity of the inlet hydrogen and the membrane thickness on the performances of an EHC were studied. The current density distribution along the EHC strictly depended on the current density supplied to the system when high relative humidity hydrogen was fed to the cell $\left(R H_{\text {chan,in }}=90 \%\right)$. A decrease of the current density distribution from $0.75 \mathrm{~A} \mathrm{~cm}^{-2}$ to $0.65 \mathrm{~A} \mathrm{~cm}^{-2}$ was observed when supplying a global current density of $0.66 \mathrm{~A} \mathrm{~cm}^{-2}$ to the $\mathrm{EHC}$, due to the membrane dehydration. 
Indeed, the relative humidity was found to decrease from $90 \%$ to $55 \%$ along the gas channels at the anode side .

The developed pseudo-2D model also proved that the stability of the current density distribution strictly depends on the local water content of the membrane. Our model gave a good prediction of both the current density distribution and the relative humidity at the anode outlet for different global current density supplied to the EHC. Nevertheless, unstable operating conditions were obtained when hydrogen with a low relative humidity was fed to the EHC. At these conditions, the EHC "consumed" water at the cathode side, giving unstable performance which could not be predicted by our numerical model.

Slight differences in water transport across the membrane were observed by using different membrane thickness. However, a lower cell voltage can be supplied to the EHC when a thinner membrane is used, increasing the compression efficiency. At $0.33 \mathrm{~A} \mathrm{~cm}^{-2}$, the specific energy consumption was around $3.5 \mathrm{kWh} \mathrm{kg}^{-1}$ (37\% efficiency), when using a $175 \mu \mathrm{m}$ thickness membrane, compared to $2.5 \mathrm{kWh} \mathrm{kg}^{-1}$ (53\% efficiency), when using a $30 \mu \mathrm{m}$ thickness membrane. Therefore, we showed that EHC systems could be highly competitive to the traditional hydrogen mechanical compressors (efficiency lower than 50\%) in the near future.

\section{Acknowledgments}

This study was partly supported by the French PIA project "Lorraine Université d'Excellence", reference ANR-15-IDEX-04-LUE and TALiSMAN project, funded by FEDER (2019-000214). 


\section{List of symbols}

$a$

A

$\alpha_{0}$

$c$

$\mathcal{D}_{\mathrm{H}_{2}, \mathrm{H}_{2} \mathrm{O}}$

$\mathcal{D}_{H_{2}}{ }^{m e m b}$

E

$E_{\varepsilon}$

$E W$

$\varepsilon 0$

$\varepsilon P T L$

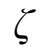

F

$i$

$i_{0}$

I

$I_{\text {loss }}$

$k_{B}$

$\lambda$

$\lambda_{a n}$

$\lambda_{\text {cat }}$

$\dot{n}_{H_{2}}$

$\dot{n}_{\mathrm{H}_{2} \mathrm{O}}$
Water activity in the membrane / -

Active area $/ \mathrm{cm}^{2}$

Charge transfer coefficient / $\mathrm{A} \mathrm{cm}^{-2}$

Total molar concentration in the PTL $/ \mathrm{mol} \mathrm{cm}^{-3}$

Binary diffusion coefficient in the PTL $/ \mathrm{cm}^{2} \mathrm{~s}^{-1}$

Water diffusion coefficient across the membrane $/ \mathrm{cm}^{2} \mathrm{~s}^{-1}$

EHC voltage / V

$\mathrm{H}_{2}$ permeation activation energy / J

Equivalent weight membrane $/ \mathrm{kg} \mathrm{mol}^{-1}$

$\mathrm{H}_{2}$ permeation pre-factor / $\mathrm{mol} \mathrm{cm}^{-1} \mathrm{~s}^{-1} \mathrm{bar}^{-1}$

PTL porosity / \%

Electro-osmotic drag coefficient / -

Faraday's constant / $\mathrm{C} \mathrm{mol}^{-1}$

Local current density / $\mathrm{A} \mathrm{cm}^{-2}$

Exchange current density / $\mathrm{A} \mathrm{cm}^{-2}$

Supplied current density / $\mathrm{A} \mathrm{cm}^{-2}$

Permeation current density / $\mathrm{A} \mathrm{cm}^{-2}$

Boltzmann's constant / J K ${ }^{-1}$

Water content / -

Water content at the anode / -

Water content at the cathode / -

$\mathrm{H}_{2}$ molar flow along the gas channel / $\mathrm{mol} \mathrm{s}^{-1}$

$\mathrm{H}_{2} \mathrm{O}$ molar flow along the gas channel / $\mathrm{mol} \mathrm{s}^{-1}$ 


\begin{tabular}{|c|c|}
\hline$\dot{N}_{H_{2}}^{P T L}$ & $\mathrm{H}_{2}$ molar flux across the PTL / $\mathrm{mol} \mathrm{cm} \mathrm{c}^{-2} \mathrm{~s}^{-1}$ \\
\hline$\dot{N}_{H_{2} O} P T L$ & $\mathrm{H}_{2} \mathrm{O}$ molar flux across the PTL / $\mathrm{mol} \mathrm{cm}^{-2} \mathrm{~s}^{-1}$ \\
\hline$\dot{N}_{\mathrm{H}_{2} \mathrm{O}}{ }^{m e m b}$ & $\mathrm{H}_{2} \mathrm{O}$ molar flux across the membrane $/ \mathrm{mol} \mathrm{cm} \mathrm{cs}^{-2}$ \\
\hline$\dot{N}_{H_{2, p e r m}}$ & $\mathrm{H}_{2}$ permeation flux across the membrane $/ \mathrm{mol} \mathrm{cm} \mathrm{cs}^{-2}$ \\
\hline$p$ & Width of active area $/ \mathrm{cm}$ \\
\hline$P_{a n}$ & Anode pressure / bar \\
\hline$P_{c a t}$ & Cathode pressure / bar \\
\hline$P_{H_{2}}^{a n}$ & Hydrogen partial pressure at anode / bar \\
\hline$P_{H_{2}}^{a n}$ & Hydrogen partial pressure at cathode / bar \\
\hline$p_{\text {sat }}(T)$ & Vapor pressure / bar \\
\hline$\rho_{d r y}$ & Density of dry membrane $/ \mathrm{kg} \mathrm{cm}^{-3}$ \\
\hline$R$ & Gas constant / $\mathrm{J} \mathrm{kg}^{-1} \mathrm{~K}^{-1}$ \\
\hline$R_{e l}$ & Total electric resistance of $\mathrm{EHC} / \Omega \mathrm{cm}^{2}$ \\
\hline$R_{m e m b}$ & Protonic resistance of the membrane $/ \Omega \mathrm{cm}^{2}$ \\
\hline$R H_{\text {chan }}$ & Relative humidity gas flow along the gas channel / \% \\
\hline$R H_{\text {chan,in }}$ & Relative humidity gas flow at the gas channel inlet / \% \\
\hline$S$ & Stoichiometry / - \\
\hline$\sigma_{m e m b}$ & Membrane proton conductivity / $\mathrm{S} \mathrm{cm}^{-1}$ \\
\hline$T$ & Temperature $/{ }^{\circ} \mathrm{C}$ \\
\hline$x_{m e m b}$ & Membrane thickness / cm \\
\hline$x_{P T L}$ & PTL thickness / cm \\
\hline
\end{tabular}




\section{References}

[1] C. Yang, J. Ogden, Int. J. Hydrog. Energy 2007, 32, 268-286.

[2] S. M. Leonard, Hydrocarb. Process. 1996, 75, 67-74.

[3] X. Jia, Y. Zhao, J. Chen, X. Peng, Int. J. Hydrog. Energy 2016, 41, 14842-14851.

[4] "HyET Hydrogen | HyET Hydrogen," can be found under https://hyethydrogen.com/, 2019.

[5] K. Fishel, G. Qian, G. Eisman, B. C. Benicewicz, in High Temp. Polym. Electrolyte Membr. Fuel Cells (Eds.: Q. Li, D. Aili, H.A. Hjuler, J.O. Jensen), Springer International Publishing, Cham, Switzerland, 2016, pp. 527-540.

[6] S. A. Grigoriev, I. G. Shtatniy, P. Millet, V. I. Porembsky, V. N. Fateev, Int. J. Hydrog. Energy 2011, 36, 4148-4155.

[7] M. Suermann, T. Kiupel, T. J. Schmidt, F. N. Büchi, J. Electrochem. Soc. 2017, 164, F1187-F1195.

[8] B. Rohland, K. Eberle, R. Ströbel, J. Scholta, J. Garche, Electrochimica Acta 1998, 43, 3841-3846.

[9] S. A. Grigoriev, K. A. Djous, P. Millet, A. A. Kalinnikov, V. I. Porembskiy, V. N. Fateev, R. Blach, in Proc Fundam. Dev. Fuel Cells 2008 Conf., Nancy, France, 2008.

[10] G. Sdanghi, G. Maranzana, A. Celzard, V. Fierro, Renew. Sustain. Energy Rev. 2019, 102, $150-170$.

[11] J. M. Moton, B. D. James, W. G. Colella, in Proc. ASME 2014 12th Int. Conf. Fuel Cell Sci. Eng. Technol., Boston, Massachusetts, USA, 2014.

[12] X. Wu, G. He, L. Yu, X. Li, ACS Sustain. Chem. Eng. 2014, 2, 75-79.

[13] R. Ströbel, M. Oszcipok, M. Fasil, B. Rohland, L. Jörissen, J. Garche, J. Power Sources 2002, 105, 208-215.

[14] R. A. Najdi, T. G. Shaban, M. J. Mourad, S. H. Karaki, in Proc 3rd Int. Conf. Adv. Comput. Tools Eng. Appl. ACTEA, Beirut, Lebanon, 2016, pp. 43-48.

[15] P. J. Bouwman, J. Konink, D. Semerel, L. Raymakers, M. Koeman, W. Kout, W. Dalhuijsen, E. Milacic, M. J. J. Mulder, ECS Trans. 2014, 64, 1009-1018.

[16] Y. Tao, H. Lee, Y. Hwang, R. Radermacher, C. Wang, Int. J. Refrig. 2015, 60, 278-288.

[17] O. Himanen, T. Hottinen, Electrochimica Acta 2006, 52, 581-588.

[18] C. Casati, P. Longhi, L. Zanderighi, F. Bianchi, J. Power Sources 2008, 180, 103-113.

[19] K. Onda, K. Ichihara, M. Nagahama, Y. Minamoto, T. Araki, J. Power Sources 2007, 164, $1-8$.

[20] L. C. Pérez, L. Brandão, J. M. Sousa, A. Mendes, Renew. Sustain. Energy Rev. 2011, 15, 169-185.

[21] L. Dubau, L. Castanheira, F. Maillard, M. Chatenet, O. Lottin, G. Maranzana, J. Dillet, A. Lamibrac, J.-C. Perrin, E. Moukheiber, et al., Wiley Interdiscip. Rev. Energy Environ. 2014, 3, 540-560.

[22] R. Lin, X. Cui, J. Shan, L. Técher, F. Xiong, Q. Zhang, Int. J. Hydrog. Energy 2015, 40, 14952-14962.

[23] A. Lamibrac, G. Maranzana, J. Dillet, O. Lottin, S. Didierjean, J. Durst, L. Dubau, F. Maillard, M. Chatenet, Energy Procedia 2012, 29, 318-324.

[24] C. Immerz, B. Bensmann, P. Trinke, M. Suermann, R. Hanke-Rauschenbach, J. Electrochem. Soc. 2018, 165, F1292-F1299.

[25] S. Abbou, J. Dillet, G. Maranzana, S. Didierjean, O. Lottin, J. Power Sources 2017, 340, 337-346.

[26] S. Abbou, J. Dillet, G. Maranzana, S. Didierjean, O. Lottin, J. Power Sources 2017, 340, 419-427.

[27] A. Goshtasbi, B. L. Pence, T. Ersal, J. Electrochem. Soc. 2016, 163, F1412-F1432. 
[28] M. Schalenbach, T. Hoefner, P. Paciok, M. Carmo, W. Lueke, D. Stolten, J. Phys. Chem. C 2015, 119, 25145-25155.

[29] M. Schalenbach, M. A. Hoeh, J. T. Gostick, W. Lueke, D. Stolten, J. Phys. Chem. C 2015, $119,25156-25169$.

[30] J. Dillet, O. Lottin, G. Maranzana, S. Didierjean, D. Conteau, C. Bonnet, J. Power Sources 2010, 195, 2795-2799.

[31] J. B. Young, B. Todd, Int. J. Heat Mass Transf. 2005, 48, 5338-5353.

[32] M. Hinaje, S. Raël, P. Noiying, D. A. Nguyen, B. Davat, Energies 2012, 5, 2724-2744.

[33] M. F. Serincan, S. Yesilyurt, Fuel Cells 2007, 7, 118-127.

[34] T. E. Springer, T. A. Zawodzinski, S. Gottesfeld, J. Electrochem. Soc. 1991, 138, 23342342.

[35] Z. Abdin, C. J. Webb, E. M. Gray, Energy 2016, 116, 1131-1144.

[36] A. Kusoglu, A. Z. Weber, Chem. Rev. 2017, 117, 987-1104.

[37] C. Vallieres, D. Winkelmann, D. Roizard, E. Favre, P. Scharfer, M. Kind, J. Membr. Sci. 2006, 278, 357-364.

[38] P. Costamagna, Chem. Eng. Sci. 2001, 56, 323-332.

[39] J. Ramousse, O. Lottin, S. Didierjean, D. Maillet, J. Power Sources 2009, 192, 435-441.

[40] A. De Giovanni, Y. Jannot, Thermal Properties Measurement of Materials, Wiley-ISTE, 2018.

[41] T. A. Zawodzinski, J. Davey, J. Valerio, S. Gottesfeld, Electrochimica Acta 1995, 40, 297-302.

[42] Y. A. Çengel, M. A. Boles, Thermodynamics: An Engineering Approach, McGraw-Hill Higher Education, New York, USA, 2006.

[43] J. Ramousse, J. Deseure, O. Lottin, S. Didierjean, D. Maillet, J. Power Sources 2005, 145, $416-427$.

[44] A. Thomas, G. Maranzana, S. Didierjean, J. Dillet, O. Lottin, J. Electrochem. Soc. 2013, 160, F191-F204. 